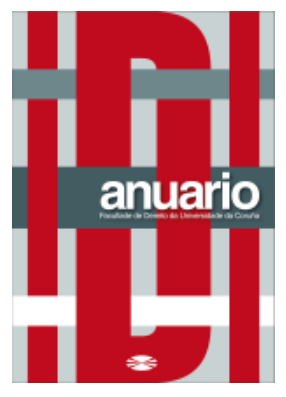

Anuario da Facultade de Dereito da Universidade da Coruña

Vol. 22 (2018), pp. 249-273

ISSNe: 2530-6324 || ISSN: 1138-039X

DOI: https://doi.org/10.17979afdudc.2018.22.0.5186

\title{
ADN: APROXIMACIÓN A LOS ALCANCES Y LÍMITES DE LA PRUEBA
}

\author{
ANDREA CRISTINA RAMALLO MACHÍN. \\ Doctora en Derecho por la Universidade da Coruña.
}

Resumen: Es evidente que se han alcanzado grandes avances en los últimos años en el campo de la biología genética, pero no significa esto que las modernas técnicas científicas puedan utilizarse sin más para basar sobre ellas la condena o la absolución de un acusado. En última instancia, nos encontramos con un problema de política legislativa. La Constitución de 1978, interpretada por el Tribunal Constitucional, impone un sistema procesal penal revestido de un conjunto de garantías, las cuales pueden chocar en aspectos concretos con el fin de la ciencia natural de alcanzar la verdad de los hechos, y no a cualquier precio, si a un precio distinto al que está dispuesto a pagar el Estado de Derecho. Plantearemos así en el presente trabajo los alcances de esta prueba.

Palabras clave: Proceso Penal. ADN. Prueba

Abstract: It is evident that there have been great advances in the field of genetic biology in recent years, but this does not mean that modern scientific techniques can be used without further to base on them the conviction or acquittal of a defendant. Ultimately, we find ourselves with a problem of legislative policy. The Constitution of 1978, interpreted by the Constitutional Court, imposes a criminal procedural system covered by a set of guarantees, which can clash in concrete aspects with the purpose of the natural science of reaching the truth of the facts, and not at any price, if at a different price than the one that is willing to pay our Rule of Law. We will propose in this paper the scope of this test.

Key words: Criminal process. DNA Test. Investigation acts 
SUMARIO: I. INTRODUCCIÓN 1. Limitaciones 1. A Alcances jurídicos 1. B Actuaciones II. CONSIDERACIONES CIENTÍFICAS 1.-La técnica 1. A El cambio III.- EL ADN EN ESPAÑA 1. Garantías. Clases IV.- ANTECEDENTES. 1. Ficheros 1.A Equipos internacionales de trabajo1.B Principios 1.C. Recomendaciones V.PRINCIPIO DE PROPORCIONALIDAD 1. Exigencias específicas 1.B. Adecuación subjetiva

\section{INTRODUCCIÓN}

La facilidad para obtener perfiles genéticos ha revolucionado la identificación humana para resolver casos criminales, así como determinar relaciones biológicas de parentesco, comúnmente paternidad. Las repeticiones cortas en tándem, más bien conocido como STRs son los marcadores genéticos más utilizados con este fin. En 1985 Alec Jeffreys implementó el uso del material genético (ADN) para identificación humana, obteniendo un patrón de bandas parecido a un código de barras al que denominó huella digital del ADN (DNA fingerprinting).

Actualmente a esta prueba se le conoce como perfil de ADN, huella genética, o simplemente prueba de ADN. Este perfil de ADN se ha demostrado que es prácticamente único e irrepetible, a excepción de los gemelos monocigotos, lo que permite diferenciar a cualquier persona de otra y establecer sus relaciones biológicas de parentesco. El ADN es el componente fundamental de los cromosomas y contiene la información hereditaria requerida para transmitir, de padres a hijos, similitudes y diferencias. El número de cromosomas de la especie humana es de 46, los cuales se agrupan en 23 pares: 22 de ellos llamados "pares autosómicos" no presentan diferencias de acuerdo al sexo; el restante, el par 23, "par sexual", tiene características diferentes determinadas por cada uno de los sexos. Los 23 pares de cromosomas están contenidos en el interior del núcleo celular. Si bien existen genes (los genes son trayectos de ADN localizados en determinadas zonas de los cromosomas) que transmiten familiarmente caracteres evidenciables, otros no lo hacen. Esta excepción que acabamos de mencionar y que de algún modo podría ser el punto débil de la técnica, la probabilidad de que un examen genético determine que el ADN de dos personas coincide sin estar relacionadas entre sí es de uno en mil millones de casos.

Cuando dos personas son hermanos, este margen de error aumenta a uno en diez mil casos. Los hermanos gemelos de por sí comparten el mismo material genético, lo que puede ser problemático a la hora de presentarse un examen de ADN como prueba judicial ante un tribunal. Algunos casos de renombre fueron reflejados por la prensa, en Francia dos hermanos gemelos idénticos fueron arrestados en la investigación de una serie de violaciones, seis en total, cometidas en la ciudad francesa de Marsella entre 
septiembre de 2012 y enero de 2013. Se trata repartidores desempleados de 24 años, Elwin y Yohan. No se puede determinar cuál es el responsable dado que las pruebas estándar de ADN no permiten diferenciar el material genético de los gemelos.

También podría darse el caso de que los dos fuesen culpables. En Argentina Provincia de Entre Ríos, Luis Wagner, condenado ya por dos violaciones ocurridas en 2010 y acusado de una tercera, dijo ante juez, fiscal y abogados, "No fui yo; fue mi hermano gemelo". Se realizaron nuevos estudios y en el Servicio de Genética del Superior Tribunal de Justicia de la Provincia se llegó a la conclusión que no se podía determinar a quién de ellos pertenecen los restos genéticos hallados en el lugar del delito, fue absuelto del tercer delito. En un análisis normal se comparan 400 pares de bases de neuclótidos que componen el ADN para diferenciar a gemelos idénticos tendrían que compararse billones de ellos. Los dos cigotos que surgen del único óvulo tienen modificaciones posteriores que pueden alterar la expresión de la secuencia del ADN. Así en 2013, un equipo de investigadores de la Universidad de Huddersfield, publicó un estudio $^{1}$ donde aseguran haber encontrado una técnica que sería capaz de diferenciar el ADN de gemelos idénticos. La técnica de los académicos se basa en la metilación del $\mathrm{ADN}_{\text {humano }}{ }^{2}$, el mecanismo que hace que ciertos genes se activen o no sin producir una alteración en la secuencia del ADN. A medida que dos hermanos gemelos envejecen, pueden realizar un sinnúmero de acciones que produce cambios mediante la metilación, como por ejemplo comenzar a fumar cigarrillos, o que uno ingrese a un trabajo de oficina y el otro a un trabajo en exteriores. El análisis de los investigadores consistiría en someter las muestras de ADN a temperaturas cada vez mayores hasta que comiencen a romperse sus enlaces de hidrógeno, y como las dos secuencias de ADN deberían tener diferentes grados de metilación, esto se expresaría en que se romperían a temperaturas diferentes - lo que puede ser medido- permitiendo así establecer la diferencia entre dos gemelos idénticos.

\section{Limitaciones}

Los investigadores saben que su técnica también tiene ciertas limitaciones. Por ejemplo, sería difícil diferenciar dos gemelos muy jóvenes, o que hayan sido criados en entornos demasiado similares como para diferenciarse. Además, está el problema que se requiere de una gran cantidad de muestras, algo que no siempre estará disponible si se utiliza para la investigación forense. Aquellas áreas de ADN que no transmiten información para características hereditarias detectables, pueden organizarse como "secuencias

\footnotetext{
${ }^{1}$ STEWART L, EVANS N, BEXON K, J, J. van der Meer D, . G. A,Williams, Differentiating between monozygotic twins through DNA methylation-specific high-resolution melt curve analysis, abril 2015.

${ }^{2}$ La metilación es la adición de un grupo metilo (- CH 3) a una molécula. En biología del desarrollo, la metilación es el principal mecanismo epigenético. Aquí la metilación consiste en la transferencia de grupos metilos a algunas de las bases cistocinas (C) del ADN situadas previa y contiguamente a una guanina $(\mathrm{G})$. Puesto que la metilación es fundamental en la regulación del silenciamiento de los genes, puede provocar alteraciones en la transcripción genética sin necesidad de que se produzca una alteración en la secuencia del ADN, siendo uno de los mecanismos responsables de la plasticidad fenotípica.
} 
repetitivas", que son pequeños fragmentos de ADN de idéntica composición que se repiten varias veces. Las técnicas de identificación por ADN nuclear se apoyan en esta propiedad de ese ADN que consiste en repetirse en determinadas zonas de los cromosomas. El ADN posee igual estructura, y por ende las mismas secuencias repetitivas en todas las células presentes en el organismo.

El análisis del ADN con fines de identificación implica el empleo de técnicas de laboratorio que utilizan diversos "marcadores" o "sistemas", los que podrían definirse conceptualmente como instrumentos que investigan esos fragmentos de ADN en los cuales se instalan las secuencias repetitivas aludidas. Los resultados que se logran de este análisis de diversas áreas de ADN configuran, en conjunto, el perfil genético propio de cada individuo. El perfil genético, así definido, tiene una capacidad discriminativa de gran potencia para diferenciar personas. Es esa cualidad del método, que le permite discriminar con altos grados de certeza, la que explica la denominación de "huellas digitales genéticas" o "fingerprints" de la literatura anglosajona, que suele utilizarse para designar este sistema de identificación. La estructura del ácido desoxirribonucleico o ADN es bien conocida: una doble cadena que gira sobre sí que contiene información hereditaria codificada solo por cuatro "letras" o nucleótidos: A, G, C y T (adenina, guanina, citosina y timina, respectivamente).

El ADN es importante porque su información es necesaria para el funcionamiento de la célula, ya que contiene las "instrucciones" para sintetizar proteínas ${ }^{3}$, quienes propiamente llevan a cabo las diferentes funciones celulares, en forma de enzimas, hormonas, receptores, transportadores, moléculas estructurales, de contracción, soporte, inmunológicas, etc. En muchas ocasiones como en este caso, convergen la ciencia biológica, la identificación por el ADN, con el mundo jurídico -la identificación por el ADN como objeto de una prueba pericial científica-. Surgiendo algunos problemas e interrogantes, basando sus soluciones, no en criterios propios de las ciencias biológicas, sino en los principios y valores constitucionales que informan el sistema procesal penal.

\section{A. Alcances jurídicos}

El mundo jurídico no puede intentar alcanzar la verdad a cualquier precio, teniendo, sin ir más lejos, una serie de limitaciones "formales", entre las que destacan la prohibición de utilizar las fuentes de prueba obtenidas con violación de los derechos fundamentales, tal y como establece el art. 11.1 LOPJ. Siendo evidentes los grandes avances que se han producido en los últimos años en el campo de la biología genética, no significa esto que las modernas técnicas científicas puedan utilizarse sin más para basar sobre ellas la condena o la absolución de un acusado. En última instancia, nos encontramos con un problema de política legislativa.

La Constitución de 1978, interpretada por el Tribunal Constitucional, impone un sistema procesal penal revestido de un conjunto de garantías, las cuales pueden chocar

\footnotetext{
${ }^{3}$ BUTLER J M. "Forensic DNA typing". Elsevier Academic Press, Burlington, MA, USA. pág. 201-240. (2005)
} 
en aspectos concretos con el fin de la ciencia natural de alcanzar la verdad de los hechos, y no a cualquier precio, si a un precio distinto al que está dispuesto a pagar nuestro Estado de Derecho. Desde que en la década de los noventa comenzó a incorporarse en los ordenamientos del entorno europeo una regulación específica sobre el uso de técnicas genéticas o de $\mathrm{ADN}$ en la investigación penal, este proceso ha experimentado una notable expansión. Se podrían destacar como fenómenos por un lado la notable expansión en el catálogo de infracciones penales cuya investigación y prueba admite el recurso a las técnicas de ADN; en segundo término, a paralela reducción en la intensidad de la imputación exigible para acceder a dichas técnicas y en tercer lugar la reducción de las garantías que rodean la aplicación de las mismas.

Encontramos los siguientes núcleos problemáticos en relación a las modernas pruebas biológicas, de las que el paradigma actual lo constituye la identificación por el ADN:

1. La naturaleza jurídica de los actos de identificación por el ADN, teniendo que diferenciarse entre actos de prueba y meros actos de investigación criminal.

2. La necesidad y/o la posibilidad de realizar intervenciones corporales con el fin de poder practicar una prueba pericial científica.

3. Toda una serie de garantías y presupuestos que han de respetarse en los casos concretos en los que se pretenda utilizar los modernos conocimientos científicos como medios jurídicos de prueba.

Teniendo en cuenta que si por prueba entendemos aquella actividad que los sujetos de un proceso realizan, bajo los principios de inmediación, contradicción y publicidad, en el juicio oral ante el órgano jurisdiccional con el fin de lograr la convicción del juzgador sobre la veracidad de las afirmaciones de hecho de las partes, y por actos de investigación penal aquella actividad que diversos sujetos, como pueden ser la policía judicial, los fiscales o los jueces de instrucción, realizan en la etapa de instrucción de un proceso penal con el fin de comprobar o averiguar la realización de hechos delictivos y a sus autores, queda patente su diferencia estructural, aunque externamente ambas actividades puedan parecer idénticas. Así, a un experto científico puede parecerle que de hecho realiza la misma actividad cuando informa sobre un hecho investigado por él a los fines de averiguar alguna circunstancia del hecho delictivo perseguido penalmente, a cuando ese informe constituye una prueba pericial. Pero, jurídicamente, la investigación se dirige a descubrir o comprobar hechos, mientras que la prueba lo que intenta es lograr la convicción del juez sobre la veracidad de los hechos afirmados por las partes. La prueba tiende a posibilitar la destrucción de la presunción de inocencia, y con ello alcanzar una sentencia condenatoria.

Los actos de investigación tienden a lograr la acusación y la defensa. Naturalmente que la distinción jurídica entre actos de mera investigación y actos de prueba se basa en el propio sistema procesal penal, como sistema acusatorio-formal, y así en los principios que lo informan. La prueba ha de realizarse en el juicio oral (art. 741 LECrim.), por lo tanto, en un juicio concentrado, informado por la contradicción y la igualdad de las 
partes, siendo valorada libremente por el juzgador. El sistema de la libre valoración, correctamente entendido, que no quiere decir en modo alguno que el juzgador sea libre de seguir sus caprichos, impresiones o sospechas, sino que debe proceder a una deducción lógica, partiendo de unos datos fijados con certeza. Por ello, la íntima convicción del órgano judicial no puede resultar nunca equivalente a despotismo, capricho o arbitrariedad ${ }^{4}$. Por ello, se ha de distinguir entre el juez sentenciador y el juez investigador, teniendo que practicarse las pruebas ante el juez sentenciador, basando éste su convicción, y así la posible condena, en las pruebas practicadas.

\section{B. Actuaciones}

Las técnicas de ADN se descomponen en una variedad de actuaciones, cada una de las cuales presenta características autónomas, por un lado, la recogida de las muestras biológicas presuntamente procedentes del autor de los hechos que se encuentran en el lugar de su comisión o en el cuerpo del delito. Las muestras obtenidas han de ser analizadas genéticamente, es decir, hay que determinar el perfil o la huella genética que permita identificar a su portador. Luego hay que proceder a elaborar igualmente el perfil de ADN, pero, ahora sí, de una persona conocida, a saber, el presunto autor de los hechos. Para ello será preciso obtener una cantidad mínima de material celular de la persona a la que se imputa la participación en el hecho delictivo mediante lo que se denomina "intervención corporal". Este material celular ha de ser, al igual que las muestras halladas, analizado genéticamente para elaborar su perfil. Por último, para asegurar una mayor eficacia en el esclarecimiento de futuros hechos delictivos se pueden almacenar el resultado del análisis genético obtenido en ficheros o bases de datos.

Como dijimos, las pruebas del ADN han supuesto un trascendente avance; que tanto en el proceso penal como en materia de filiación tienen una especial importancia, considerándose por algunos sectores como una incuestionable prueba. Por sus propios condicionamientos, van a exigir que se permita una excepción a las reglas sobre las pruebas en el proceso penal. Y dicha excepción, también admitida para otra serie de actos que se desarrollan en la fase de investigación de un proceso penal, constituye un supuesto de la denominada prueba preconstituída.

De tal manera que determinados actos de investigación, que por su propia naturaleza no pueden ser realizados en el juicio oral, podrán, no obstante, obtener la naturaleza de actos probatorios, siempre que se garantice la contradicción de las partes mediante su reproducción en el juicio oral. Pero aquí nos encontramos con dos problemas diversos: a) La pericia no puede volver a practicarse en el juicio oral por su propia naturaleza (por ejemplo: los métodos alcoholimétricos). Entonces la solución jurisprudencial consiste en permitir la realización de la prueba con anterioridad al juicio oral, pero, en garantía del principio de contradicción, habrán de acudir al juicio oral los peritos que realizaron tales actos de prueba con el fin de ratificar sus informes, pudiendo alegar al respecto las partes lo que tengan por conveniente para su defensa.

\footnotetext{
${ }^{4}$ PÉREZ-CRUZ M, A, Derecho Procesal Penal, Thomson Reuters - Civitas, 2010, pp. 493-494.
} 
b) La pericia ha sido realizada en la etapa de instrucción, pero los sujetos que la han efectuado, a los que se ha de acudir por la complejidad de los métodos de investigación que han de emplearse, y por la necesidad de dotar a tales técnicas de la máxima fiabilidad posible, no son otros que determinadas instituciones oficiales cualificadas, como pueden ser la Escuela de Medicina Legal, el Instituto de Toxicología, los Laboratorios de Policía Científica, etc. Estas son las soluciones de nuestra jurisprudencia, pero ha de tenerse bien presente que también la doctrina precisa que, respecto al segundo supuesto, alguna de las partes impugne la prueba pericial, negando su veracidad o criticando su contenido, o en muchos casos la cadena de custodia de las muestras por tanto deberá someterse a contradicción en el juicio oral el informe pericial presentado, por lo que habrán de ser citados a la etapa probatoria del juicio oral los peritos en cuestión al objeto de presentar sus informes periciales.

\section{CONSIDERACIONES CIENTÍFICAS}

\section{1.-La técnica}

La identificación de las personas con fines de investigación criminal mediante ciertas mediciones corporales físicas o de otro tipo, no es nueva. Contamos a este respecto con diversas técnicas biométricas que se han ido desarrollando, siendo una de las primeras, o al menos, la que más éxitos cosechó en su momento, la ideada en el siglo XIX por Alphonse Bertillon con sus mediciones antropométricas, basándose en la invariabilidad de ciertas partes del cuerpo, en particular algunas de la cabeza y de las manos; y la fiabilidad y extensión que fueron ganando las huellas dactilares, mediante la técnica de la dactiloscopia, que se basa en el carácter perenne, inmutable y diversiforme de aquellas, y que fue introducida en España por FEDERICO OLÓRIZ. ${ }^{5}$ A la hora de seleccionar una técnica biométrica determinada se pondera de forma especial la relación existente entre su fiabilidad y su coste, no sólo desde el punto de vista económico (eficiencia), sino también de su eficacia, rapidez y sencillez en la práctica concreta de la identificación, así como que pueda transferirse a algún soporte informático, (y, en su caso, red) en particular a un fichero en el que ya figuren los datos biométricos adaptados con fines identificativos.

El uso extendido de las técnicas biométricas plantea diversos problemas éticos y jurídicos. En cuanto a los primeros, se alega el riesgo de deshumanización de las personas, dado que son sistemas burocráticos y despersonalizados de identificación: supone una intromisión excesiva en la intimidad y la vida privada de las personas, incluyendo la cuestión de qué información podría hacerse pública y cuál no; puede utilizarse con fines de vigilancia y control de las personas más que de identificación, incluso de restricción de sus movimientos. Muchos de los aspectos jurídicos vinculados

\footnotetext{
5 OLÓRIZ F. Manual para la identificación de delincuentes de Madrid, Bruselas (1911). Sus investigaciones dactiloscópicas le llevaron a elaborar, a partir de los trabajos de Alphonse Bertillon, una técnica de identificación personal a partir de las huellas dactilares.
} 
con estas técnicas biométricas surgen también en relación con el uso de los perfiles de ADN.

Si los datos biométricos pueden ser considerados legalmente como datos de carácter personal; cuáles son los derechos fundamentales que pueden verse afectados: el derecho a la protección de datos de carácter personal y a la intimidad, la libertad ambulatoria, al poder estar condicionados los movimientos a la superación de las identificaciones biométricas; prohibición de discriminación o estigmatización por las características biológicas; la dignidad de la persona, por el riego de instrumentalización del ser humano; e incluso, el derecho a la integridad física en relación con algunas técnicas, como es la medición del iris o de la retina o la obtención de muestras biológicas para realizar los perfiles de ADN, por muy remotos que puedan ser los riesgos. También es posible que se implanten estas técnicas sin el conocimiento del usuario (p. ej., medición de la temperatura en determinadas circunstancias aisladas). En la actualidad han ganado interés las identificaciones a través de los perfiles de ADN y su utilización es habitual, no solo con fines de investigación criminal, sino también para otros, como la determinación del parentesco biológico, la identificación de restos cadavéricos y la localización de desaparecidos, especialmente en situaciones catastróficas naturales o provocadas. Una de las características de nuestro material genético básico, la molécula de $\mathrm{ADN}$, es la presencia de diferencias entre individuos, esto es, la presencia de polimorfismos.

Dentro del ADN debemos distinguir el ADN codificante y el no codificante. Algunas de las diferencias se observan en ADN codificante y reflejan las variaciones que existen entre individuos en sus proteínas. Precisamente el primer polimorfismo de ADN fue descubierto en ADN codificante por WHYMAN y WHITE en 1980. El ADN codificante es, sin embargo, muy poco variable salvo la región de los HLA, cuya variabilidad ya era conocida por los productos de expresión. La mayor parte del ADN humano es no codificante, lo que significa que no está transcrito a ARN y, en consecuencia, no tiene relación con las variaciones proteicas. ${ }^{6}$ Desde hace unas décadas se está trabajando en otras técnicas biométricas más sencillas y no menos fiables, así como con el poderosísimo recurso instrumental que aportan las Tecnologías de la Información y de la Comunicación (TIC).

El interés de estos procedimientos no se limita a la investigación criminal, sino que se está extendiendo a otros usos civiles respeto de los cuales se requiere una identificación segura de algunas personas, como son los relacionados con transacciones comerciales, (el comercio y otras transacciones electrónicas), sistemas bancarios y financieros, sistemas de identificación sanitaria, el acceso a lugares restringidos, control de los movimientos de las poblaciones inmigrantes, en particular sobre el origen étnico y geográfico y las relaciones familiares de estas personas, etc. Por consiguiente siguiendo

\footnotetext{
${ }^{6}$ WYMAN, A. R., WHITE, Y. R., "A higly polymorphic locus in human DNA", Proceedings of the National Academy of Sciences, EEUU., vol. 77, 1980, págs. 6754 y ss.
} 
a ROMEO CASABONA ${ }^{7}$, quien hace referencia a la terminología usada por ejemplo por MARINO TAPIADOR ${ }^{8}$ desde un punto de vista jurídico, la Biometría puede ser definida como el conjunto de técnicas y procedimientos automatizados de identificación y verificación individual de las personas por medio de sus características biológicas.

Estas características han de ser inherentes a cada individuo, intransferibles y no transportables ni susceptibles de cesión (como ocurre con los documentos de identificación), y pueden ser: 1.- Anatómico-físicas (estáticas), como son las huellas dactilares, el iris, la retina, la forma de la mano, el ADN, reconocimiento facial, etc. 2.Relativas al comportamiento (dinámicas): la firma manuscrita, la forma de caminar, los gestos, la forma de pulsar las teclas de un aparato o instrumento, la voz. La validez de estas técnicas está condicionada a la concurrencia de determinadas características y circunstancias, por lo que han de ser: 1.-Universales, es decir, que las posean todos los seres humanos. 2.-Individualizados, que permitan diferenciar a unos individuos de otros. 3.-Irrepetibles, lo que garantiza que cada individuo posea esos rasgos de forma excluyente. 4.-Permanentes, que no se modifiquen con el paso del tiempo. 5.Inalterables, en el sentido de que no se puedan modificar a voluntad de las personas, incluso aunque sea por procedimientos técnicos u otros o, en términos más amplios, que no permitan su manipulación o la suplantación de la identidad. 6.-Detección sencilla. 7.Fiables, en el sentido de su precisión identificadora.

\section{A El cambio}

El descubrimiento del polimorfismo del ADN en estas regiones fue lo que revolucionó la genética forense, porque se trata de un ADN con una enorme variabilidad entre individuos $\mathrm{y}$ por tanto con un gran potencial identificador. Los sucesivos descubrimientos han redundado en una mayor definición en la identificación. 1.- Fueron descubiertas las regiones Minisatélite o VNTR (Variable Number of Tandem Repeats) cuya aplicación forense se restringía a los casos en los que se podían obtener determinadas cantidades de ADN no degradado. Con posterioridad se descubrieron las regiones Microsatelites o STR (Short Tandem Repeats), más pequeñas que los VNTRs, y que podían ser analizadas mediante técnicas de amplificación génica, PCR (Polymerase Chain Reaction) lo que permitió su aplicación a un gran número de casos forenses en las que se obtenían cantidades críticas de ADN degradado.

El inicio de la historia de las aplicaciones forenses de los polimorfismos de ADN se puede situar en 1984 cuando WELLER, JEFFREYS y WILSON ${ }^{9}$ descubrieron una región de ADN situada en uno de los intrones (partes no codificantes) del gen de la mioglobina humana, formada por cuatro repeticiones en tándem de una secuencia de 33

\footnotetext{
${ }^{7}$ ROMEO CASABONA C. "Los identificadores del ADN en el sistema de justicia penal". Thomson Reuters, 2010.

${ }^{8}$ MARINO TAPIADOR M, SIGÜENZA JUAN A, "Tecnologías biométricas aplicadas a la seguridad". Editorial RAMA, 2005.

${ }^{9}$ WELLER, P., JEFFREYS, A. J., WILSON, V., "Organization of the human myoglobin gene", EMBO Journal, vol. 3, 1984, págs. 439 y ss
} 
pares de bases (bp). En 1985, JEFFEYS, WILSON y THEIN ${ }^{10}$ basándose en que esta región hipervariable mostraba una cierta similitud con la secuencia de otros genes hipervariables, diseñaron sondas de ADN, denominadas sondas multilocus, que podían determinar muchas de estas regiones hipervariables simultáneamente. Jeffreys y sus colaboradores consideraron que estos patrones serían prácticamente específicos para cada individuo, y los denominaron "DNA fingerprints" (huellas genéticas). Tanto en el caso de los VNTRs como en el del los STRs el principio básico del polimorfismo genético reside en la variación del número de veces que se repite en tandem una secuencia determinada (de 9-60 bases en el caso de VNTRs y de 1-7 bases en el caso de STRs). En ambos casos se trata de regiones de ADN no codificante y, por tanto, de su análisis no se obtiene información alguna acerca de características físicas o fenotípicas del individuo (tales como la predisposición individual a padecer enfermedades de base genética).

Si bien el análisis de polimorfismos de ADN repetitivo supuso un gran avance en la Genética Forense, y aún son en la actualidad utilizados, principalmente en investigaciones biológicas de la paternidad, su uso forense posee algunas limitaciones. La primera es la imposibilidad de análisis de muestras minúsculas (por insuficiencia de la cantidad de ADN que se puede extraer) como pequeñas manchas de sangre, de esperma o pelos, lo que ocurre en la mayor parte del trabajo forense, en el ámbito de la investigación criminal en el que nos hemos de conformar con mínimas muestras encontradas en el lugar del crimen o en la víctima. Otro problema era el análisis de muestras degradadas, tan frecuentes en casos médico-legales, con las que puede ser imposible obtener resultados con SLPs ya que las sondas usadas detectan frecuentemente fragmentos muy grandes (de más de $5000 \mathrm{bp}$ ) que se rompen con facilidad. Una limitación menor pero añadida, debida a la laboriosidad del método, es el tiempo de análisis, que implica que un problema médicolegal (una mancha o una paternidad) no pueda ser solucionado en menos de tres días con SLPs. 2.- El análisis de polimorfismos de ADN mediante la reacción en cadena de la polimerasa (PCR) solucionó muchos de estos problemas y actualmente la mayoría de los vestigios biológicos de interés criminal se analizan utilizando esta técnica.

La PCR es una técnica de amplificación in vitro de pequeños segmentos de ADN, con la que a partir de una cadena única se pueden hacer millones de copias, de modo que el producto amplificado puede ser fácilmente analizado, incluso sin recurrir al uso de sondas. Los marcadores genéticos de interés médico legal susceptibles de análisis por PCR incluyen polimorfismos genéticos de ADN codificante (especialmente Hla Clase II), polimorfismos de ADN minisatélite (AMPFLPs), polimorfismos de ADN microsatélite (STRs), fragmentos hipervariables de ADN mitocondrial, haplotipos de cromosoma Y y loci específicos de cromosoma X e Y para el diagnóstico del sexo. Los microsatélites STRs, short tandem repeats, son, con mucha diferencia, los marcadores genéticos más utilizados en el campo forense y consisten en repeticiones de dos a seis nucleótidos que se repiten un número muy variable de veces entre individuos. Las

\footnotetext{
${ }^{10}$ JEFFREYS, A. J., WILSON, V., THEIN, S. L., "Hipervariable minisatellite regions in human DNA", Nature, vol. 314, 1985, págs. 67 y ss.
} 
principales ventajas de los microsatélites son su estabilidad en muestras degradadas debido a su pequeño tamaño y la posibilidad de PCR múltiplex, amplificando varios STR simultáneamente, que otorga a los laboratorios forenses una capacidad de discriminación notable. Entre los STRs, las repeticiones de dos nucleótidos son abundantísimas en el genoma, y de hecho, son los marcadores más utilizados en los análisis clínicos de ligamiento de marcadores genéticos a enfermedades, pero su uso en el campo forense se ha restringido debido a la frecuente presencia de bandas adicionales que hace que su seguridad técnica pueda ser cuestionada. Las repeticiones de cuatro nucleótidos son las más utilizadas en el campo forense, pues unen una gran fiabilidad diagnóstica y un elevado polimorfismo.

En la actualidad, los STRs tetraméricos(llamados así porque la unidad de secuencia que se repite en tándem es de cuatro bases) son los sistemas cuyo uso se ha generalizado en los laboratorios de genética forense por tratarse de sistemas con un gran poder de discriminación y una gran sensibilidad y especificidad para el análisis de la variabilidad humana a partir de muestras forenses. En un principio fue estandarizado el uso de STRs, simples, no extraordinariamente polimórficos pero muy seguros en el fenotipado con sistemas electroforéticos manuales. Con la introducción de los secuenciadores automáticos fue posible la estandarización de STRs complejos e hipervariables. Se caracterizan éstos por no poseer una repetición regular de unidades, pero poseer, en cambio, una extraordinaria variabilidad entre individuos. Otra de las ventajas del uso de secuenciadores automáticos es que la tecnología de detección mediante láser de los productos de amplificación marcados con fluorocromos en los que están basados permite analizar numerosos STRs simultáneamente a partir le la misma muestra (PCR múltiplex), lo que simplifica notablemente el trabajo forense y la posible realización de bases de datos de ADN elaboradas con fines de investigación criminal.

También se ha avanzado notablemente en la automatización total del proceso de análisis, por lo que la seguridad analítica es, actualmente, muy elevada. Entre los individuos de una población puede tener diferentes formas alternas denominadas alelos. Estas secuencias permiten diferenciar a un individuo de otro y, al heredarse de padres a hijos, también permite establecer relaciones biológicas de parentesco, por lo que se les conoce como marcadores genéticos o marcadores 30 moleculares (por estar en la molécula del $\mathrm{ADN}$ ). Cabe señalar que para cada marcador una persona tendrá dos alelos, uno materno y otro paterno, y a dicha combinación de alelos que recibimos de nuestros padres se le denomina genotipo. Específicamente las secuencias o marcadores empleados para realizar una prueba de ADN se caracterizan por tener repeticiones cortas en tándem, y son ampliamente conocidos por sus siglas en inglés como STRs (short tandem repeats) o microsatélites. A lo largo del genoma se encuentran miles de STRs que pueden ser usados como marcadores moleculares. Como su nombre lo dice, los STRs se componen de secuencias cortas repetidas, por ejemplo, GATA, formando diversos alelos que se nombran por el número de veces que se encuentre la secuencia repetida; por ejemplo, el alelo 6 presentará seis veces la secuencia (p. ejem. GATA, GATA, GATA, GATA, GATA, GATA), y en una población podrían existir los alelos 6 , $7,8,9,10,11,12,13,14$, etc. El par de alelos o genotipo de una persona para cada 
marcador STR (p. ejem. 6/9), permite diferenciarlo o relacionarlo con otras personas. Cuando la persona presenta dos alelos diferentes (uno materno y otro paterno), se dice que su genotipo es heterocigoto; mientras cuando tiene un solo alelo se asume que recibió el mismo alelo de ambos padres, y se dice que su genotipo es homocigoto para el STR en cuestión. En una pareja de heterocigotos para alelos diferentes se pueden generar cuatro genotipos distintos en sus hijos, lo que permite diferenciar individuos estrechamente relacionados como los hermanos. Un perfil de ADN, que también suele llamarse huella genética, se genera obteniendo los genotipos de varios STRs, formando un código que presumiblemente puede llegar a ser único e irrepetible $(6 / 9,12 / 16,17 / 21$, $22 / 23$, etc.).

\section{EL ADN EN ESPAÑA}

La utilización del ADN para realizar análisis en el ámbito de la Administración de justicia ha adquirido importancia en algunos procesos civiles (demandas de paternidad) y penales, en particular en aquellos hechos delictivos que pueden dejar vestigios biológicos del autor sobre la víctima, el lugar o los instrumentos del delito, así como de la víctima sobre el autor o sus pertenencias (delitos violentos, como el homicidio o contra la libertad sexual de las personas). La policía científica española comenzó a trabajar con muestras de ADN a principios de los años noventa, así la Sección de Biología del Instituto de Toxicología de Madrid emitió un informe en la investigación de un presunto delito de violación en que por primera vez se utilizó la tecnología del ADN, ocurrió en 1991 y los resultados fueron exculpatorios.

No cabe duda de que la trascendencia de esta prueba en el proceso penal en la investigación de delitos graves y de su autoría, han hecho necesario el desarrollo de un marco legal que regulara esta materia, sus aspectos de mayor importancia garantizando la protección de determinados derechos de las personas. La sección de biología del Instituto Nacional de Toxicología y el Laboratorio del Servicio Central de Policía Científica están en condiciones de aplicar la compleja tecnología del ADN como método de identificación genética con plenas garantías de fiabilidad, vemos que la evolución de este tema es relativamente reciente, pues en el año 1992 una Sentencia del Tribunal Supremo cuestiona la infalibilidad de este tipo de pruebas, ${ }^{11}$ su aceptación ha sido progresiva, de hecho en ese momento se utilizaban 8 marcadores de ADN y hoy en día las fuerzas de seguridad utilizan 16 marcadores más el sexo.

Es un instrumento particularmente útil para la identificación de cadáveres y la localización de desaparecidos (p. ej., en casos de accidentes en catástrofes naturales), o por interés histórico. Por tal motivo se ha ido incorporando firmemente en la práctica forense, habiendo dado lugar incluso a una especialidad dentro de la Medicina Forense:

\footnotetext{
${ }^{11}$ (...) “... El análisis de ADN, medio probatorio que propuso (...) la defensa del acusado y que fue declarada no procedente, lo fue porque está acreditado que dicha técnica está en período de experimentación (...) por lo que hasta ahora sus resultados no son fiables..." STS 1/01/1992 FJ $631^{\circ}$ de 13 de julio.
} 
la Genética Forense. Con relación a las bases de datos de perfiles de ADN en España, la Policía Científica contaba con dos bases de datos: una con perfiles de ADN donado por familiares de personas desaparecidas, llamada Humanitas, y otra, Veritas, con perfiles de muestras recogidas durante las investigaciones de delitos.

Hay variedad de problemas que se pueden suscitar en relación con esta materia, adelantando que no es fácil dar una respuesta uniforme y segura a todos ellos. Un tratamiento unitario de las intervenciones corporales no parece posible. Dentro del concepto de intervenciones corporales encajan actuaciones tan diversas y con tan distinto contenido invasivo como la toma de huellas dactilares, extracción de sangre, obtención de saliva, corte de cabello, examen de la cavidad vaginal o anal, exploración corporal superficial, el cacheo externo, extracción de orina, un examen radiológico, y algunas otras medidas que podrían afectar gravemente a la salud. Es evidente que no puede construirse un régimen común a medidas tan diferentes.

Los derechos fundamentales que pueden estar afectados son muy variados y cambian según el tipo de medida a la que nos enfrentemos. Dadas estas características técnicas, así como su extraordinaria precisión, se han convertido en un instrumento muy valioso para la moderna pericia forense y, lo que es más importante, para un más satisfactorio ejercicio del derecho a la tutela judicial efectiva y una respuesta más eficaz a las exigencias de la sociedad respecto a la persecución de los responsables de los delitos.

\section{Garantías. Clases.}

Estas técnicas originan problemas que hacen necesario asegurar que se realicen con las suficientes garantías técnicas, procesales y de respeto a los derechos fundamentales afectados. Podríamos resumir, dando importancia a los que son de mayor relevancia en nuestra investigación los siguientes grupos:

a) naturaleza y valoración procesal de sus resultados o perfiles de ADN;

b) posible afectación de algunos derechos fundamentales del sujeto que se somete a examen;

c) la creación de archivos con los resultados de los análisis de ADN (perfiles de ADN) realizados a los autores de algún delito, o sobre las muestras o vestigios biológicos obtenidos en la escena del crimen,

Existen dos clases de ADN: el codificante y el no codificante, si hacemos una comparación de los perfiles de ADN con las huellas dactilares vemos que estas últimas solo aportan información identificativa, pero los perfiles de ADN, además, indican el sexo de la persona, su etnia y su filiación y/o paternidad (ascendientes y descendientes biológicos), entre otras informaciones de carácter personal, circunstancia que incide directamente en que aquél merece ya por sí mismo una mayor protección. El primero de ellos es el que contiene la secuencia de los genes, el material genético al que corresponde la función de producir («expresar» a través del ARN) las proteínas que dan lugar a los rasgos físicos de los individuos (el fenotipo), los cuales son transmitidos por 
los mecanismos de la herencia. De este material puede obtenerse información sobre la salud presente o futura (en términos predictivos de seguridad o de predisposición o susceptibilidad) del sujeto sometido a los análisis pertinentes, así como de los riesgos de transmitir alguna enfermedad hereditaria a su descendencia. Sin embargo, presenta escasa variabilidad de unos individuos a otros, a salvo del HLA (antígenos leucocitarios humanos). De ahí el interés que existe en limitar el acceso a este material, la realización de análisis sobre el mismo y la difusión de los resultados de estas pruebas.

El otro ADN, el no codificante, carece de las capacidades del anterior -no se expresa en proteínas a través del ARN-, pero es mucho más abundante y, sin entrar ahora en sus funciones -por lo demás, no muy bien conocidas todavía-, presenta como característica más destacable su gran variabilidad de unas personas a otras o, lo que es lo mismo, su elevado polimorfismo. El acceso al ADN no codificante para realizar los estudios de los perfiles comporta asimismo la posibilidad de acceder a todo el ADN, es decir, también al codificante: todo el ADN (codificante o no codificante) se halla ubicado de forma lineal y continua como secuencias de bases nitrogenadas en el núcleo de cada célula del cuerpo, de modo que sólo una vez iniciada su manipulación en el laboratorio se puede seleccionar la parte -genética o no genética- que se desea someter a estudio. Las características de la muestra en cuanto tal no permite separar previamente una parte $-\mathrm{O}$ segmentos- del ADN de la otra -u otros-; el acceso para los estudios forenses pertinentes es a todo el ADN.

España es uno de los pocos países que hasta LO 10/2007 no había regulado la creación ni la utilización de estos bancos de material identificativo, si bien se quiso de algún modo paliar esta laguna con la reforma de la Ley de Enjuiciamiento Criminal, regulando el uso de las pruebas de ADN en las investigaciones y permitiendo que el juez instructor pueda autorizar la muestras de sospechosos de delitos graves. ${ }^{12}$ Con fecha 8 de octubre de 2003 se aprobó la Ley Orgánica 10/2007, reguladora de la Base de datos Policial sobre Identificadores Obtenidos a través de ADN. En este archivo se volcarían todos los perfiles genéticos de los cuatro registros existentes en las Fuerzas de Seguridad del Estado.

\section{ANTECEDENTES}

La utilización de las técnicas de ADN para el esclarecimiento de hechos delictivos ha supuesto un enorme cambio legal que la acompañara. Esto no quiere decir que no existieran archivos con anterioridad, los había, con un soporte legal discutible hasta la aprobación de la Ley de 2007.

Los antecedentes prelegislativos muestran que tanto esta materia relativa a la base de datos policial con perfiles de ADN como el procedimiento de obtención y manejo de muestras para una investigación policial concreta, estaba previsto y hubiera sido

\footnotetext{
${ }^{12}$ Ley Orgánica 15/2003, de 25 de noviembre, que dio nueva redacción a los Arts. 326 y 363, y previsto la constitución de la Comisión nacional sobre el uso forense del ADN.
} 
deseable, que se regulasen en un cuerpo normativo único, aunque no haya sido finalmente éste el criterio adoptado por el legislador, probablemente por motivos de oportunidad política. El primer antecedente a mencionar es la Unión Europea, a través de la Recomendación Núm. R (92) 1 del Comité de Ministros, sobre el uso del ADN en la justicia penal.

Aunque de forma breve, esta Recomendación trata tanto de los aspectos jurídicos relacionados con la obtención de las muestras biológicas y su análisis pericial como los relativos a las bases de datos de perfiles de ADN, siempre en el ámbito penal. La mayor parte de sus principios reguladores continúan manteniendo su validez, sin perjuicio de que el tiempo pasado haya impuesto ciertos cambios de perspectiva. Desde ese punto de vista su trascendencia aumenta pues ha podido influir en la legislación de los Estados miembros de la Unión Europea.

El Poder Legislativo la necesidad de regular legalmente esta clase de materias, incluidas, como se ve, las relativas a las pruebas biológicas sobre la paternidad. Luego, el Ministerio de Justicia creó un grupo de trabajo multidisciplinario, a partir del cual se fijaron con mayor precisión algunos de los principios y garantías que debían regir a las pruebas de ADN en el proceso penal, así como las bases de datos con estas finalidades. Este trabajo cristalizó en un "Borrador de Anteproyecto de Ley reguladora de las bases de datos de ADN" de 1999 (adaptado a la LORD con una nueva versión en 2000), que el Gobierno no llegó a aprobar como Proyecto de Ley y por ello no llegó a remitirse a las Cortes Generales. En estos trabajos prelegislativos se basa la primera regulación de las pruebas de ADN en materia penal, que aconteció por la LO 15/2003, y también se tuvo en cuenta en la LO 10/2007.

\section{Ficheros}

Con anterioridad al régimen legal que ha establecido la LO 10/ 2007 fueron creados varios ficheros de perfiles de ADN y de vestigios biológicos con fines de investigación criminal al servicio de los cuerpos y fuerzas de seguridad del Estado. No obstante, es importante destacar que los ficheros creados no lo han sido de forma exclusiva con tales objetivos, sino también con otros de identificación de cadáveres o determinación del paradero de personas desaparecidas en diversas circunstancias no delictivas (accidentes, catástrofes, suicidios, etc.), lo que ha venido rindiendo también un servicio de asistencia civil muy apreciado por los ciudadanos.

El período de tiempo en el que ha habido una carencia normativa específica sobre esta materia dejó a los ficheros policiales existentes entonces sin la cobertura legal necesaria, a pesar de los esfuerzos del Gobierno de adaptar aquéllos a la legislación sucesiva sobre protección de datos de carácter general mediante disposiciones de rango administrativo, puesto que tampoco era suficiente a ese respecto el marco que dispensaban la LORTAD y la LOPD. El Ministerio de Justicia e Interior dictó una Orden por la que se regulaban 
los ficheros con datos de carácter personal gestionados por dicho Ministerio ${ }^{13}$, dando así cumplimiento a la disposición adicional segunda, núm. 2. de la LORTAD entonces vigente. En su anexo figuraba un fichero de $\mathrm{ADN}$, sobre el que se indicaba que el responsable del mismo era la Dirección General de la Policía, que la finalidad era la identificación de implicados en delitos mediante bandas de ADN, para usos de investigación policial; y que respecto a dichos implicados se recogerían en el fichero las infracciones penales, el nombre y apellidos y el patrón de bandas de ADN, siendo grabada la información por los gestores a partir de los asuntos investigados. Con posterioridad, y como ya comentáramos, se crean los ficheros para la identificación genética de restos cadavéricos «ADN Humanitas y o «ADN Veritas» ${ }^{14}$.

Las disposiciones ministeriales de sustento normativo de estos ficheros fueron sustituidas por otra posterior del 20 de junio de 2002, que adaptaba el régimen de los ficheros existentes a las exigencias legales de la nueva Ley sobre protección de datos (LORD). La Guardia Civil, a su vez, cuenta con una Base de Datos de ADN de Interés Criminal (ADNIC), creada con anterioridad a la Ley vigente de 2007. En ella se archivan los datos obtenidos de vestigios biológicos hallados en la escena del crimen y de otras muestras biológicas, también desconocidas, relacionadas con una investigación criminal, las cuales podrán compararse con otras muestras de origen conocido (muestras indubitadas) ordenadas por el Juez. Parece ser que tanto unos datos como otros se incorporan al archivo. También se creó un fichero para la identificación genética de personas desaparecidas y de cadáveres sin identificar (fichero «FÉNIX»), por la Orden Ministerial de 18 de marzo de $1998 .^{15}$

\section{A. Equipos internacionales de trabajo}

En 1988 el Grupo Español fue aceptado como grupo de trabajo por la International Society for Forensic Genetics, en adelante ISFG que desde su creación emite recomendaciones y normas sobre la aplicación de polimorfismos genéticos a las pericias médico legales. En materia de ADN, siguiendo la idea general de gestión de calidad antes expuesta, se realizan ejercicios colaborativos coordinados por el grupo español a nivel del Sudoeste europeo incluyendo laboratorios portugueses, franceses y españoles.

\footnotetext{
${ }^{13}$ OM de 26 de julio de 1994 (BOE, de 27 de julio). Ténganse en cuenta, asimismo, la Resolución de 30 de junio de 1995 de la Dirección General de la Policía, por la que se dictan instrucciones sobre determinados aspectos de los ficheros policiales de datos de carácter personal, y la Orden de 2 de febrero de 1995. del Ministerio de Justicia e Interior, por la que se aprueba la primera relación de países con protección de datos de carácter personal equiparable a la española, a los electos de transferencia internacional de datos.

${ }^{14} \mathrm{Su}$ finalidad es colaborar con la Administración de Justicia en la represión de infracciones penales, con la identificación genética de vestigios biológicos recogidos en la investigación de hechos presuntamente delictivos o de muestras de la misma naturaleza, a solicitud o disposición de autoridades a las que la Ley atribuya competencia para exigir el tratamiento de los datos que resulten, mediante el cotejo de los perfiles genéticos investigados con los obtenidos de las muestras de origen conocido, de acuerdo a lo establecido en el artículo 22.4 de la Ley Orgánica 15/1999 sobre Protección de Datos de Carácter Personal.

${ }^{15} 23 . \mathrm{La}$ OM d 11 de noviembre de 2004 adapta el régimen de esto ficheros a LOPD.
} 
En el Grupo Español de la ISFG están integrados un total de 30 laboratorios entre los que se encuentra el Instituto Nacional de Toxicología, cátedras de Medicina Legal, institutos de Medicina Legal, laboratorios policiales del Ministerio del Interior, laboratorios de departamentos universitarios y laboratorios privados.

La práctica totalidad de la pericia médico legal que se realiza en España y Portugal en materia de biología forense, ya sea oficial o privada, es realizada por laboratorios del Grupo, lo que no impide, ya que no existe ninguna disposición legal que así lo establezca, que laboratorios que no pertenezcan al grupo realicen pericias para su utilización ante los Tribunales.

Desde 1989 la ISFG emite recomendaciones sobre el empleo de polimorfismos genéticos aplicados a pericias médico- legales que normalmente son incorporados por los grupos de trabajos nacionales a sus respectivas recomendaciones y normas. En España las primeras recomendaciones sobre el empleo de marcadores genéticos con fines forenses fueron aprobadas en 1987 circunscritas a la pericia en investigación biológica de paternidad.

En 1992 fue aprobada por el grupo español de la ISFG una nueva normativa, que incluye ya los aspectos concernientes al análisis de vestigios biológicos de interés criminal. En relación con el polimorfismo del ADN, la ISFG emitió sus primeras recomendaciones a través de su comisión de ADN en $1989 .{ }^{16}$

La llegada de la técnica de la PCR solucionó muchos de los problemas que presentan las SLPs pero suscitó nuevas cuestiones que fueron contempladas en las recomendaciones que en 1992 elaboró la Comisión de ADN en técnicas de PCR222. En ellas se prestó especial atención a la nomenclatura de los sistemas, a la posibilidad de contaminación (recomendándose extraer el ADN en un área distinta al área de amplificación) y a la cuantificación de ADN, para lo que se recomiendan procedimientos de slot-blot.

En 1987 la Sociedad Internacional de Hemogenética Forense (ISFH), hoy de Genética forense (ISFG) creó una comisión de ADN para discutir "el excitante desarrollo del uso de la prueba de ADN en el contexto médico legal". La ISFG es una sociedad internacional que reúne la práctica totalidad de especialistas en genética forense a nivel europeo y tiene asimismo una importante implantación en los demás continentes.

\section{B. Principios}

El principio de proporcionalidad, según la interpretación de algunos ordenamientos europeos, exige que cualquier intervención corporal forzosa tendrá que ser autorizada expresamente y para cada caso concreto por la autoridad judicial competente. Así lo

16 En ellas se hace una declaración general inicial basada en tres puntos básicos: 1. La tecnología de ADN recombinante es una herramienta esencial para el desarrollo de la prueba forense, pero es solamente una parte del peritaje médico-legal. 2. Para alcanzar una alta reproducibilidad y garantizar el principio de una segunda opinión, ciertos criterios tienen que ser adoptados en la investigación de los polimorfismos de ADN. 3. Se establecen los requisitos de control de calidad y comparación de resultados dentro de un mismo laboratorio y entre laboratorios. 
estableció la Ley Procesal Penal alemana de 7 de enero de 1975 en su parágrafo 81, con posterioridad el Código de Procedimiento Penal de Italia aprobado por Decreto de 22 de septiembre de 1988 en su artículo 244, según el cual, su práctica se acordará "...mediante decreto motivado cuando sea necesario averiguar las huellas y los demás efectos materiales del delito..." y 245, el Código del Proceso Penal portugués de 1987 en su artículo 171 y 172. Este último precepto establece que "si alguien pretende eximirse o impedir cualquier examen debido podrá ser compelido por decisión de la autoridad judicial competente". ${ }^{17}$

La primera necesidad de regulación de la prueba de ADN se sintió lógicamente desde un punto de vista científico. Fue en los laboratorios, con la práctica diaria, donde se advirtieron las consecuencias de un mal uso de dichas pruebas y fueron los científicos los que inicialmente se concienciaron de la conveniencia de establecer una normativa que uniformase el proceso de averiguación del perfil genético del individuo, mucho antes de que los juristas y legisladores se percataran de la importancia de la existencia de dicha legislación.

En EE.UU, los problemas planteados durante el proceso penal en el caso «O. J. Simpson» por la defensa ${ }^{18}$, revelaron la importancia de la coordinación de los peritos en genética forense y la demostración de la necesidad de una especialización real, antes de poder llevar a cabo una pericia y presentarla como tal ante los Tribunales, así como la posible exigencia de implantar programas de control de calidad en los laboratorios que vayan a realizar este tipo de pericias. Los científicos en distintas agrupaciones empezaron a llevar a cabo una "autoregulación subjetiva", que no tiene obviamente los efectos de una ley, si bien ha servido para un control propio de los laboratorios y para el alcance de un alto nivel en la pericia en muchos casos. Sin embargo, esta autoregulación se redacta, sin colaboración de juristas y legisladores quienes por otra parte presentan un desconocimiento casi absoluto sobre la materia.

\section{C. Recomendaciones}

Estas recomendaciones convenidas por los científicos no tienen fuerza vinculante frente a la sociedad, y el Estado no contaba, antes de la regulación, por tanto, con mecanismos para poder exigir que los laboratorios se sometan a controles. Como ejemplo de ello pueden servirnos las particularmente detalladas previsiones de la Circular del Ministerio del Interior del Reino Unido ${ }^{19}$, de 1995 sobre el Banco Nacional de Datos de ADN, en desarrollo de la Ley de Justicia Penal y Orden Público, modificada en 1994. En efecto,

\footnotetext{
17 SEOANE SPIEGELBERG, J. L., "Recepción en el proceso de nuevos métodos de investigación científica y derechos fundamentales”, Medicina legal, ed. CGPJ, Madrid, 1993.

${ }^{18}$ Caso People vs. Simpson, sentencia del 3 de octubre de 1995.

${ }^{19}$ De carácter Administrativo, en desarrollo de la Ley de Justicia Penal y Orden Público.
} 
el art. 49 establece: “...Las muestras se deben precintar, embalar y etiquetar en presencia del donante y se deben enviar a la organización que lleve a cabo el perfil por uno de los procedimientos de entrega aprobados. Se facilitarán los siguientes detalles en el impreso ADN - 1: i) el nombre, fecha de nacimiento, sexo, y apariencia étnica de la persona; ii) el tipo de muestra: frotado bucal o pelos; iii) la fecha de obtención de la muestra; iv) el nombre, rango y número del agente que toma la muestra; v) el número de identificación de la muestra: vi) el código del cuerpo/comisaría; y vii) el número del arresto phoenix/número del informe de citación. En los casos en que no sea posible la entrega en un plazo de 48 horas, las muestras se conservarán a -20 C" (junto con la información identificativa necesaria) ...”. Especialmente riguroso es el art. 50 respecto a la aceptación de las muestras por parte del laboratorio encargado de realizar los perfiles de $\mathrm{ADN}$ (análisis de $\mathrm{ADN}$ ) puesto que prescribe que deben rechazarse aquellas muestras que no lleguen en condiciones satisfactorias, sin la debida identificación o cuya consistencia sea motivo de duda.

En Norteamérica, a partir del "caso Castro", se creó la TWGDAM (Technical Work Group for DNA Analysis and Methods, hoy este grupo se denomina SWGDAM) y, simultáneamente, en Europa la EDNAP (European DNA Profiling Group) con la idea de estudiar los problemas de aplicación forense de los polimorfismos de ADN, estandarizar metodologías y trabajar con la idea de una cualificación común, incluyendo controles de calidad.

En estos momentos puede sostenerse que las pruebas de ADN tienen una seguridad muy elevada. La Sociedad Internacional de Homogenética Forense (ISFH) y el Grupo Europeo sobre Perfiles de ADN (EDNAP) y con posterioridad el Grupo Español y Portugués de la Sociedad Intarnacional de Genética Forense (GEP-ISFG), cuya evolución explicaremos más adelante, han fijado como uno de sus objetivos prioritarios garantizar la eficacia de los laboratorios que realizan las pruebas y coordinar sus técnicas, mediante la emisión de las recomendaciones oportunas. Así la EDNAP, que cuenta con representantes de todos los países de la Unión Europea y de la EFTA se convirtió en grupo oficial de trabajo de la entonces ISFH en 1991. Desde ese mismo año la comisión de ADN de la ISFG incluye normalmente como expertos externos representantes de la EDNAP y SWGDAM. El primer esfuerzo fue la estandarización de las sondas y enzimas utilizados en los análisis a nivel europeo, esto era una primera necesidad, ya que si cada laboratorio utilizase sus propias sondas y enzimas, no sólo sería imposible compartir bases de datos y estudios poblacionales, sino que se dificultaba enormemente que otro laboratorio pudiese repetir la prueba por lo que no había posibilidad de segundas opiniones o contrapericias, tan importantes en un sistema médico -legal justo, como la propia pericia.

En 1993 la Comisión de ADN emitió un informe sobre algunos aspectos del informe del National Research Council (NCR) norteamericano, con el que coincide en aspectos como acreditación y regulación de laboratorios, pero del que discrepa en la influencia de las subpoblaciones en las grandes bases de datos poblacionales para la estima de frecuencias. Este problema afecta específicamente a las bases de datos del FBI, debido a 
la abundancia de distintos grupos poblacionales en Estados Unidos, pero no tiene gran trascendencia en poblaciones europeas. En la reunión de la Comisión de ADN celebrada en Venecia en 1994, se analizó de forma exclusiva la aplicación de la PCR al análisis de polimorfismos de $\mathrm{ADN}$ en criminalística y se trataron numerosos aspectos técnicos. La American Association of Blood Banks (AABB), por otra parte, emite también recomendaciones y estándares para los laboratorios que realicen sus programas de control de calidad.

Todos los grupos de trabajo de la ISFG y muchas sociedades nacionales de Medicina legal emiten recomendaciones que, en general, se remiten a las publicadas por la comisión de ADN de la ISFG. Los juristas y legisladores han reclamado la necesidad de regulación positiva a raíz de este tipo de recomendaciones al percatarse de la trascendencia social y práctica de los descubrimientos científicos. Por su parte, los jueces y tribunales, en la interpretación de esta prueba, habrán de tener muy en cuenta la fiabilidad de los resultados ofrecidos, atendiendo a la solvencia científica y técnica de los laboratorios que efectúan esos análisis.

Es evidente que la validez de la prueba dependerá de su correcta realización técnicocientífica, esto es, como indicábamos más arriba, que se realice por personal cualificado, siguiendo los protocolos correctos y prestando atención escrupulosa a las técnicas de aislamiento para evitar las contaminaciones durante el trabajo, etc. Para que ésta ofrezca garantías de certeza es necesario que el centro científico que la lleve a cabo cuente con medios materiales y técnicos suficientes, y con un equipo de expertos de reconocida competencia. Por ello, cuando se plantea en un proceso la práctica de esta prueba se encarga su realización a organismos de reconocido prestigio en la materia, como, por ejemplo, el Instituto Nacional de Toxicología. En lo que se refiere al Derecho español, hasta hace poco tiempo no estaban regulados los diversos aspectos relacionados con los perfiles de $\mathrm{ADN}$ en el proceso penal, como tampoco los procedimientos de obtención, tratamiento, conservación y registro de las muestras y de los marcadores obtenidos mediante el análisis de aquéllas.

Por fin el Legislador ha establecido de forma muy breve los principios y criterios para la obtención de muestras biológicas -dubitadas e indubitadas- y su utilización en el proceso, así como para un desarrollo por parte del Gobierno de los diversos aspectos técnico-científicos relacionados con las muestras, lo que contrasta con la minuciosidad prevista en iniciativas anteriores, en las que se inspira esta regulación. Con posterioridad ha sido objeto de regulación, asimismo, la base de datos policial sobre identificadores obtenidos a partir del ADN. En la actualidad es necesario que estos laboratorios hayan sido acreditados. ${ }^{20}$

${ }^{20}$ El art. 5.2 de la LO 10/2007, de 8 de octubre, reguladora de la base de datos policial sobre identificadores obtenidos a partir de ADN, "solo podrán realizar análisis del ADN para identificación genética en los casos contemplados en esta Ley los laboratorios acreditados a tal fin por la Comisión Nacional para el uso forense del ADN que superen los controles periódicos de calidad a que deban someterse" 
Como consecuencia de ello se elaboran textos internacionales sobre la materia entre los que cabe destacar la Resolución del Parlamento Europeo sobre los problemas éticos y jurídicos de la manipulación genética, de 16 de marzo de $1989,{ }^{21}$ más recientemente el Convenio sobre los Derechos Humanos y la Biomedicina de 4 de abril de 1997, del Consejo de Europa, la Declaración Universal de la UNESCO sobre el Genoma Humano y los Derechos Humanos, de 11 de noviembre de 1997 y la Declaración sobre los Principios de Actuación en la Investigación Genética aprobada en Heidelberg, el 21 de marzo de 1996 por el Consejo de la HUGO (Organización del Genoma Humano) con fundamento en unas recomendaciones elaboradas por su Comité de Aspectos Éticos, Jurídicos y Sociales. Los mencionados textos internacionales contienen principios y pronunciamientos genéricos acerca de algunas de las cuestiones relacionadas con el Genoma, con escasas referencias a su aplicación forense. Es, sin embargo, en la Recomendación del Consejo de Europa 1 (92) que se estudia a continuación donde se aborda por primera vez de modo frontal esta materia.

La Recomendación 1 (92) sobre la utilización del análisis de ADN dentro del marco de la Administración de la Justicia Penal; que trata cuestiones relacionadas con la aplicación forense del ADN. El Acuerdo fue adoptado por el Comité de Ministros el 10 de febrero de 1992 en su reunión $470^{\mathrm{a}}$, y de conformidad con el procedimiento de estas reuniones, los representantes de Alemania, Holanda y Noruega se reservaron el derecho de sus gobiernos de cumplir o no el punto 8 de la Recomendación, y el gobierno de Dinamarca el derecho de cumplirla o no en su conjunto.

El Consejo de Europa a la vista de las diferencias de postura entre los miembros del grupo de trabajo preparatorio optó en la Recomendación por prever "los principios, mientras que los detalles son determinados por la legislación de los Estados miembros afectados". La Recomendación por tanto contiene continuas referencias al ordenamiento interno de los países miembros, quienes deberán precisar en su legislación todas las cuestiones que se plantean.

El memorandum explicativo de la Recomendación establece que las técnicas de ADN conllevan un riesgo, no sólo en relación a los derechos fundamentales como el derecho a la vida privada y familiar, el derecho a un proceso debido y el respeto al cuerpo humano. A la vista de esta potencial injerencia la incorporación al sistema de justicia criminal requiere la adopción de ciertas garantías. El Comité de Ministros, convencido de la necesidad de proceder de acuerdo con una política criminal común dirigida a la protección de las personas y la sociedad en que viven.

Las técnicas de análisis de ADN pueden ofrecer ventajas a la Administración de Justicia Penal, en especial en la determinación de la inocencia o la culpabilidad; pero se debe tener plenamente en cuenta y no vulnerar principios fundamentales como la dignidad

21 Diario Oficial de las Comunidades Europeas, 17 de abril de 1989. 
inherente de la persona y el respeto al cuerpo humano, los derechos de defensa y el principio de proporcionalidad en el ámbito de la justicia penal.

\section{V.-PRINCIPIO DE PROPORCIONALIDAD}

Una exigencia común y constante para la constitucionalidad de cualquier medida restrictiva de derechos fundamentales, entre ellas las que supongan una injerencia en los derechos a la integridad física y a la intimidad (por todas. SSTC 120/1990. 7/1994 y 143/1994), y más en particular de las medidas restrictivas de derechos fundamentales adoptadas en el curso de un proceso penal (por todas, SSTC 37/1989, 85/1994 y 54/1996) viene determinada por la estricta observancia del principio de proporcionalidad. Así pues, la decisión de la autoridad judicial de acordar la práctica de la prueba debe estar presidida por el principio de proporcionalidad de sacrificio.

Conforme a este principio deben ponderarse los intereses que entran en conflicto, a saber, los intereses de un particular, consistentes en el respeto de sus derechos fundamentales, por un lado, y el interés público en la persecución de los responsables de hechos delictivos, por otro. Debe tenerse en cuenta que en esta segunda parte de los elementos de ponderación pueden hallarse, asimismo, derechos fundamentales de personas concretas (p. ej., el derecho a la tutela judicial efectiva por parte de la víctima o incluso, del propio imputado, art. $24 \mathrm{CE}){ }^{22}$

De acuerdo con el principio de proporcionalidad, la medida limitadora de un derecho fundamental debe ser idónea, necesaria y proporcionada en relación con un fin constitucionalmente legítimo. Dicho de otro modo, tal principio impone comprobar lo siguiente:

a) si tal medida es susceptible de conseguir el objetivo propuesto (juicio de idoneidad),

b) si, además, es necesaria, en el sentido de que no exista otra medida más moderada para la consecución de tal propósito con igual eficacia (juicio de necesidad);

c) si la misma es ponderada o equilibrada, por derivarse de ella más beneficios o ventajas para el interés general que perjuicios sobre otros bienes o valores en conflicto (juicio de proporcionalidad en sentido estricto).

El principio de proporcionalidad comporta proceder a una ponderación entre la intromisión en la integridad y la intimidad del sujeto y otros derechos fundamentales que pudieran ser sometidos a alguna restricción, por un lado, y la finalidad perseguida, por otro, teniendo en cuenta, en este caso, la gravedad del delito, el grado de importancia de la medida y las perspectivas de éxito de la misma.

\footnotetext{
${ }^{22}$ GOMEZ AMIGO L. "Las intervenciones corporales como diligencias de investigación Penal" Aranzadi, 2003. Pag. 97 ADN: Huellas Genéticas en el Proceso Penal.
} 
Del cumplimiento de estos presupuestos dependerá que la concreta medida adoptada y practicada respete los derechos fundamentales en juego. Sólo de este modo la fuente de prueba obtenida será lícita y podrá ser utilizada a efectos probatorios en el proceso penal, O dicho de otro modo, si la medida adoptada no cumple dichos presupuestos de legitimidad constitucional, con la misma se habrán vulnerado los derechos fundamentales afectados y la fuente de prueba deberá ser considerada ilícita. En consecuencia, sus resultados no podrán ser introducidos en el juicio oral a través de ningún medio de prueba. ${ }^{23}$

Esta ponderación ha de ser realizada por el Juez y plasmarse asimismo en la motivación escrita de tal acuerdo con el fin de que, en virtud del principio d contradicción, el sujeto pueda oponerse si manifiesta su desacuerdo con la decisión judicial y ejercer de este modo su derecho de defensa. Por consiguiente, que el Juez exprese mediante una resolución motivada el resultado de su ponderación, consecuente con la aplicación del principio de proporcionalidad, es casi tan importante como la ponderación misma.

\section{Exigencias específicas}

a) Exclusión si la obtención de la muestra puede comportar un daño físico o psíquico: En ningún caso podrá acordarse la práctica de una intervención corporal cuando pueda suponer bien objetiva, bien subjetivamente, para quien tenga la obligación de soportarla un riesgo o quebranto para su salud (STC 7/1994). Ya vimos que esta situación, sin embargo, ocurrirá de forma muy excepcional.

b) Obtención de la muestra que resulte menos perjudicial, de entre todas las formas existentes para obtener una muestra biológica de un individuo para proceder a la realización de un análisis de ADN, el juez deberá ordenar que se practique aquella que resulte menos lesiva o perjudicial. Es decir, que si basta con la saliva, no estará justificada la orden de extraer sangre.

c) Personal apto para realizar la extracción de la muestra, según la STC 7/1994, la ejecución de tales intervenciones corporales se habrá de efectuar por personal sanitario, que deberá ser personal médico especializado en el supuesto de intervenciones graves que lo requieran por sus características. Así deberá serlo si se trata de llevar a cabo una extracción de sangre, pero parece excesivo requerir la intervención de un profesional sanitario para tomar muestras de saliva de la cavidad bucal con un hisopo estéril.

d) Respeto de la dignidad humana, la práctica de la intervención se ha de llevar a cabo con respeto a la dignidad de la persona, sin que pueda en ningún caso constituir, en sí misma o por la forma de realizarla, un trato inhumano o degradante, aspectos estos sobre los que pesa una prohibición absoluta (arts. 10.1 y $15 \mathrm{CE}$ ).

\footnotetext{
${ }^{23} \mathrm{El}$ art 11.1 LOPJ “.... En todo tipo de procedimiento se respetarán las reglas de la buena fe. No surtirán efecto las pruebas obtenidas, directa o indirectamente violentando los derechos o libertades fundamentales..."
} 
e) Limitación para ciertos delitos, nada explícito se señala en el conjunto de normas aplicables sobre los delitos a los que queda reservada la práctica de obtención de identificadores a partir del análisis del ADN. El principio de proporcionalidad conduce a reservar este tipo de prueba, por lo que comporta, según lo visto más arriba, de afectación a derechos fundamentales, a delitos particularmente graves. En esta dirección, los tribunales han limitado la práctica de la prueba de ADN a delitos graves, en aplicación del principio de proporcionalidad.

Por ejemplo, la SAP de Sevilla de 24 de septiembre de 2002 resuelve la apelación contra una sentencia absolutoria dictada en un juicio de faltas. El recurso se fundamentaba en indefensión por denegación de la prueba de ADN. La denuncia versaba sobre unos escupitajos que presuntamente el denunciado había lanzado en la fachada de la casa del denunciante. El recurrente pretendía que se analizaran los mismos y se cotejaran con el ADN del denunciado. La Audiencia desestima el recurso con fundamento en los criterios de racionalidad y proporcionalidad, señalando que "...este criterio conduce a negar que para acreditar infracciones de mínima gravedad y trascendencia social, como lo es una falta semipública, sean exigibles medios probatorios como una identificación de $\mathrm{ADN}$, técnicamente complejos y muy costosos económicamente y que además exigen la colaboración del imputado aportando una muestra de sus fluidos corporales. El despliegue de medios públicos, materiales y humanos, que sería necesario para llevar a cabo la prueba propuesta no se justifica por el interés público en juego en el supuesto enjuiciado, cuando tales recursos limitados apenas sí dan abasto para abarcar los casos de grave trascendencia en los que habitualmente se recurre a este medio de investigación (...)".

Debe recordarse que sí se ha contemplado un criterio legal para la inscripción de los identificadores obtenidos a partir del $\mathrm{ADN}$ en la base de datos policial creada por la LO $10 / 2007$.

\section{A. Adecuación subjetiva.}

Por lo que respecta a la adecuación subjetiva al principio de proporcionalidad, un sector doctrinal entiende que la legislación vigente incumple dicho principio. Así el art. 363.II LECrim dispone que "...el Juez de Instrucción podrá acordar, en resolución motivada, la obtención de muestras biológicas del sospechoso...". Por su parte, la Disposición adicional tercera de la LO 10/2007 habla de la posibilidad de "...la toma de muestras y fluidos del sospechoso, detenido o imputado...". Así se ha dicho que las diligencias de investigación limitativas de derechos fundamentales sólo pueden aplicarse sobre aquél a quien el órgano jurisdiccional, con base en indicios serios o sospechas fundadas, le atribuya la participación en el hecho punible. Por ello, según un sector de la doctrina, solo podrían practicarse sobre aquél a quien se imputa judicialmente la participación en el hecho punible investigado, con base en indicios fundados y suficientes, pero no sobre el mero sospechoso. 
Una vez aprobada la LO 10/2007, parece que esta interpretación más amplía resulta la más conforme con la voluntad del Legislador, dado que se distingue claramente entre imputado y sospechoso, abarcando ahora también a los detenidos. El principal problema respecto a la mención del sospechoso, es definir su concepto jurídico y delimitar su estatuto jurídico en relación con la realización de las pruebas de ADN y, en particular, la inscripción de sus perfiles en la base de datos policial y el ejercicio de los derechos relacionados con esa inscripción.

Especial mención merece en este sentido la reciente Reforma operada por la Ley Orgánica 13/2015, de 5 de octubre, de modificación de la Ley de Enjuiciamiento Criminal que sustituye el vocablo imputado por investigado y encausado, según la fase procesal.

Con lo que quedan abiertas futuras interpretaciones terminológicas con su correlato jurídico, de vital importancia a la hora de determinar la posibilidad de realización de la prueba y su posterior inscripción en las bases de datos.

\section{BIBLIOGRAFÍA}

BUTLER J M. "Forensic DNA typing”. Elsevier Academic Press, Burlington, MA, USA. pág. 201-240. (2005).

GOMEZ AMIGO L. "Las intervenciones corporales como diligencias de investigación Penal” Aranzadi, 2003. Pag. 97 ADN: Huellas Genéticas en el Proceso Penal.

JEFFREYS, A. J., WILSON, V., THEIN, S. L., "Hipervariable minisatellite regions in human DNA", Nature, vol. 314, 1985, págs. 67 y ss.

MARINO TAPIADOR M, SIGÜENZA JUAN A, "Tecnologías biométricas aplicadas a la seguridad". Editorial RAMA, 2005.

ROMEO CASABONA C. "Los identificadores del ADN en el sistema de justicia penal". Thomson Reuters, 2010.

OLÓRIZ F. Manual para la identificación de delincuentes de Madrid, Bruselas. (1911).

PÉREZ-CRUZ M, A, Derecho Procesal Penal, Thomson Reuters - Civitas, 2010, pp. 493-494.

SEOANE SPIEGELBERG, J. L., "Recepción en el proceso de nuevos métodos de investigación científica y derechos fundamentales”, Medicina legal, ed. CGPJ, Madrid, 1993 
STEWART L, EVANS N, BEXON K, J, J. van der Meer D, . G. A,Williams, Differentiating between monozygotic twins through DNA methylation-specific highresolution melt curve analysis, abril 2015.

WELLER, P., JEFFREYS, A. J., WILSON, V., "Organization of the human myoglobin gene", EMBO Journal, vol. 3, 1984, págs. 439 y ss

WYMAN, A. R., WHITE, Y. R., "A higly polymorphic locus in human DNA", Proceedings of the National Academy of Sciences, EEUU., vol. 77, 1980, págs. $6754 \mathrm{y}$ ss. 